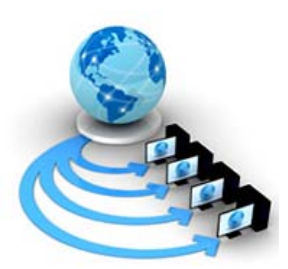

Volume 8, No. 9, November-December 2017

International Journal of Advanced Research in Computer Science

REVIEW ARTICLE

Available Online at www.ijarcs.info

\title{
TRELLIS CODED MODULATION AND BIT INTERLEAVING: A REVIEW
}

\author{
Nisha \\ M.Tech Scholar: Department of ECE \\ UIET, MDU \\ Rohtak, Haryana, India
}

\author{
Mr. Manoj Ahlawat \\ Assistant Professor: Department of ECE \\ UIET, MDU \\ Rohtak, Haryana, India
}

\begin{abstract}
This research article represents the literature review on study of coded convolution codes like trellis coded modulation (TCM) and bit interleaved coded modulation (BICM) for robust error correction of codes. In wireless communication error correction codes and interleaving have an important application due to fading. Reviewed research papers have TCM and BICM with different techniques and methods used in it. Papers show different modulation schemes used with TCM for various applications. Different algorithms are used with BICM for improving bit error rate and improving bandwidth efficiency in reviewed papers. Different techniques like Iterative decoding and Constellation mapping are used with BICM and TCM to improve Bit error rate (BER) and signal to noise ratio (SNR).
\end{abstract}

Keywords: TCM, BICM, BER, SNR.

\section{INTRODUCTION}

In wireless communication, signal is transmitted wirelessly (without wires) from source to destination. But the signal at the receiver end, we get, is distorted due to different obstacles in non line of sight that is called fading. To overcome fading error detection and correction codes are used. Error detection is the recognition of error due to niose or other deterioration during transmission. Error correction is the recognition of errors and reformation of the original data with no error. Error detection and correction can be done by simply adding some extra bits to a message which receiver can use to check compactness of the delivered message. Error correction codes are differentiated asconvolution codes and block codes. Block codes are processed on a segment basis and convolution codes on symbol basis. Convolution codes are the error correcting codes in which parity symbols are generated by sliding application (convolution of encoder over data) of a Boolean polynomial function to a data steam. Convolution codes are used to attain reliable data transfer in fields like mobile communication, satellite communication etc. So in today's wireless communication convolution codes can be used in different schemes like in trellis coded modulation.

\section{A. Trellis coded modulation (TCM)}

Trellis coded modulation is the composition of coding which is done digital and modulation which is done in analog as a single function. 'Trellis' stands for the use of trellis (also called convolution code). It has non linear nature of performance and its performance is measured by coding gain over an uncoded signal. By the use of convolutional coding TCM is bandwidth efficient modulation. The trellis coded modulation function contains a Trellis code and a Constellation Mapper. The function of Convolution coder of rate $\mathrm{R}=\mathrm{N} / \mathrm{N}+1$ and a $\mathrm{M}$-ary signal mapper that maps $\mathrm{M}=$ $2^{\mathrm{N}}$ input points into bigger constellation of $\mathrm{M}=2^{\mathrm{N}+1}$ constellation points are combined in TCM.

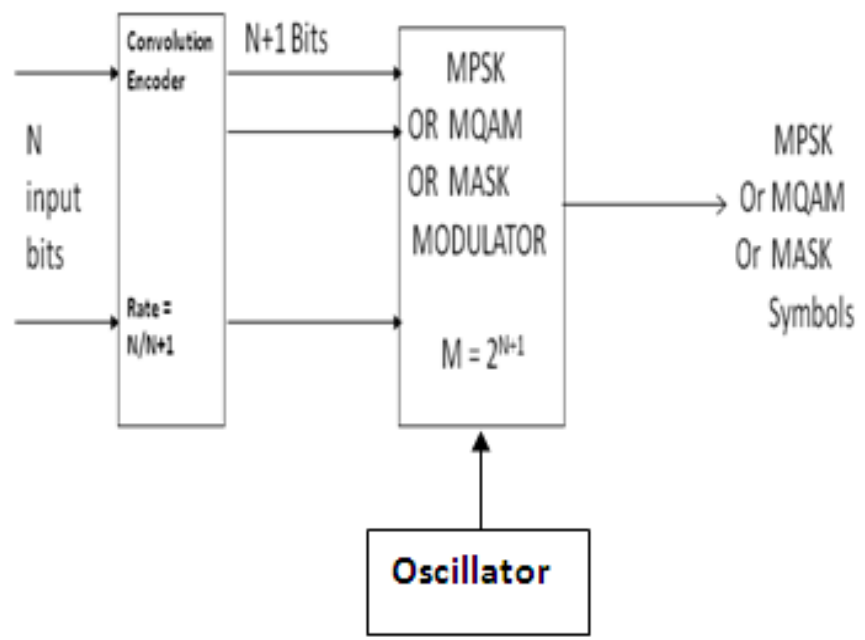

Fig. General diagram of Trellis Coded Modulation

\section{B. INTERLEAVING:}

Interleaving is a process of making system more efficient, fast and reliable by reorganising a group of symbols. Interleaving can be used in arranging storage in RAM, error correction in data and in multidimensional data structure.

\section{BIT INTERLEAVING:}

In bit interleaving the data is shuffled so that the burst errors are converted into random error. Time division multiplexing (TDM), telecommunication and computer memory uses bit interleaving.

\section{BIT INTERLEAVED CODED MODULATION:}

Bit interleaved coded modulation is considered as the powerful strategy to achieve high data rates with general signal constellation. It uses powerful family of binary codes with any modulation format. 


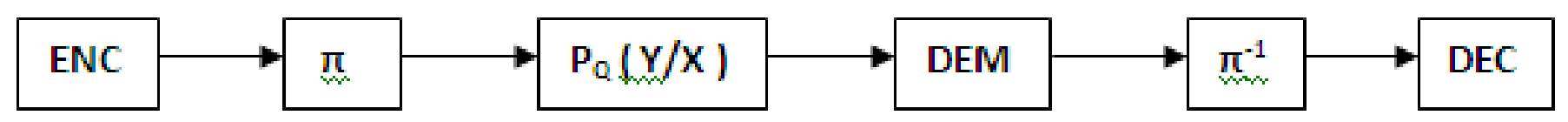

Fig.2. Block diagram of transmission with bit interleaved coded modulation. Where $\pi$ denotes interleaving at the bit level.

[1] BICM for a binary code can be obtained by sequencing an encoder (ENC) with a memory less modulator over a specific signal set (x) throughout a bit interleaver $\pi$ and one to one binary tagging map $(\mu)$. The code sequence is interleaved firstly and again it is subdivided into sub sequences of specific bits. In the end the resulting signal is transmitted on the vector channel.

In BICM [10] channel encoder and modulator are distinguished by a bit level interleaver, increasing the flexibility in choosing the code rate and constellation individually.

\section{LITERATURE SURVEY}

This section provides a brief summary of work held on Trellis coded modulation and Bit interleaving coded modulation.

In [2] Lee - Fang Wei suggested the use of multidimensional TCM schemes like four, eight, or 16 dimensional constellation instead of two - dimensional with same complexity but better tolerance to phase ambiguities.

In [3] author analysed the performance of trellis coded MPSK in the faded environment. In the analysis the effect of fading is overcome by techniques like phase locked loop, pilot tone calibration, interleaving and deinterleaving. Analysis states the increase in gain depends upon lower bit error rate, size of interleaver and Doppler frequency.

In [4] author gives an idea of multiple trellis coded modulation ( MTCM) with two - state trellis codes for symmetric Multiple phase shift keying modulation and Analog modulation gives three $\mathrm{db}$ gain without any loss in information bit rate compared to conventional trellis coded modulation, though some additional computations in two state MTCM is needed. With advancements number of states and modulation schemes can be extended.

In [5] Michel L. Moher and John H. Lodge describes a technique TCMP (trellis coded modulation with pilot sequences) to overcome the drawback of TCM that is TCM need coherent detection for achieving full optimization. In TCMP trellis coded data and pilot sequences are multiplexed together for coherent detection to provide robust performance in presence of fading.

G.Caire, G.Taricco, E.Biglieri in [6] give a brief idea about Bit interleaving coded modulation (BICM) and in what ways it is better than trellis coded modulation. Paper is focussed on evaluation of its performance on different fading channel like AWGN and Rayleigh fading. Comparative study results shows superiority of bit interleaved codes over Viterbi's orthogonal Convolutional codes (OCC). BICM specifications involve minimum hamming distance, minimum Euclidean distance and number of nearest neighbours which indicates the performance of BICM.

Vincent K.N Lau [7] proposed an error correcting method, Adaptive Bit interleaved coded modulation for bandwidth efficiency in wireless system. Bit interleaving is preferred over TCM due to bit by bit interleaving instead of symbols. In ABICM according to channel conditions code rates and modulation level are varied. By less sufficiency feedback link - in good channel state modulation level and code rate are increased and vice versa in band channel state to maintain targeted error level. ABICM focused on multilevel puncturing and interleaving. In terms of signal to noise ratio and output significant performance improvement is obtained.

Author of [8] proposed a bandwidth efficient method over fading channels that is BICM - ID. Compared to trellis modulation soft decision iterative decoding has large diversity with small Euclidean distance. According to results Performance efficiency of BCIM- ID depends on error free feedback.

Naghi H. Tran and Ha H. Nguyen [9] investigated different mapping techniques for 8-ary constellation in BICM - ID. Main is put on Euclidean distance and Mutual information for mapping techniques. Free squared Euclidean distance (FED) distance parameters are also discussed in this paper. After comparing different mapping schemes Io Maximised mapping scheme was found to be most suitable for 8-ary constellation BICM - ID system. Results shown that BER (bit error rate) at high SNR for an uncoded system oven an additive white Gaussian noise channel (AWGN) is minimized by Io mapping in 8-ary constellation.

In [10] Hierarchical constellations are used to protect a data stream from channel impairments. BER performance of single data stream is improved by using Constellation. Multiplexer and interleaver are also used for Nakagami-m fading channels.

Bit interleaved coded modulation with iterative decoding in two way relaying communication (TWRC) is proposed in [11]. For multiple access (MA) phase iterative decoding is adopted relaying on quaternary code representation. Bit error probability is successfully deducted in this paper with the use of iterative decoding and XOR based network coding at the relay.

Table I. Literature survey table

\begin{tabular}{|l|l|l|l|l|}
\hline Year & Authors & Title & Contribution & Result \\
\hline 1987 & Lee-Fang-Wei[2] & $\begin{array}{l}\text { Trellis coded } \\
\text { modulation with }\end{array}$ & $\begin{array}{l}\text { Multidimensional } \\
\text { TCM scheme like four, }\end{array}$ & $\begin{array}{l}\text { Better tolerance to phase } \\
\text { ambiguities }\end{array}$ \\
\hline
\end{tabular}




\begin{tabular}{|c|c|c|c|c|}
\hline & & $\begin{array}{l}\text { multidimensional } \\
\text { constellation }\end{array}$ & $\begin{array}{l}\text { eight and sixteen } \\
\text { dimension } \\
\text { constellation are } \\
\text { suggested }\end{array}$ & \\
\hline 1987 & $\begin{array}{l}\text { Dariush divsalar and } \\
\text { Marvin K. Simon[3] }\end{array}$ & $\begin{array}{l}\text { TCM for } \\
\text { transmission(4800- } \\
9600 \mathrm{bps}) \text { over a } \\
\text { fading mobile } \\
\text { satellite channel }\end{array}$ & $\begin{array}{l}\text { phase locked loop, } \\
\text { pilot tone calibration, } \\
\text { interleaving and } \\
\text { deinterleaving } \\
\text { techniques are } \\
\text { suggested for TCM to } \\
\text { overcome fading }\end{array}$ & $\begin{array}{l}\text { Bit error rate is analysed to increase } \\
\text { gain }\end{array}$ \\
\hline 1988 & $\begin{array}{l}\text { Dariush Divsalar and } \\
\text { Marvin K. Simon[4] }\end{array}$ & $\begin{array}{l}\text { Multiple trellis } \\
\text { coded modulation } \\
(\mathrm{MTCM})\end{array}$ & $\begin{array}{l}\text { multiple trellis coded } \\
\text { modulation with } 2- \\
\text { state trellis codes for } \\
\text { proportionate } 1 \text { MPSK } \\
\text { and AM modulations } \\
\text { are used }\end{array}$ & $\begin{array}{l}3 \mathrm{db} \text { gain is obtained compared to } \\
\text { conventional TCM }\end{array}$ \\
\hline 1989 & $\begin{array}{l}\text { Michel L. Moher and } \\
\text { John H. Lodge[5] }\end{array}$ & $\begin{array}{l}\text { TCMP-A } \\
\text { Modulation and } \\
\text { coding strategy for } \\
\text { Racian Fading } \\
\text { Channels }\end{array}$ & $\begin{array}{l}\text { trellis coded } \\
\text { modulation with pilot } \\
\text { sequences is } \\
\text { introduced }\end{array}$ & $\begin{array}{l}\text { Robust performance in presence of } \\
\text { fading }\end{array}$ \\
\hline 1997 & $\begin{array}{l}\text { G.caire, G.Taricco and } \\
\text { E.Biglieri[6] }\end{array}$ & $\begin{array}{l}\text { Bit interleaved } \\
\text { coded modulation } \\
(\mathrm{BICM})\end{array}$ & $\begin{array}{l}\text { A brief about BICM } \\
\text { and its comparison } \\
\text { with TCM }\end{array}$ & $\begin{array}{l}\text { BICM performance analysis over } \\
\text { several fading channel }\end{array}$ \\
\hline 1999 & Vincent K.N. Lau[7] & $\begin{array}{l}\text { Performance of } \\
\text { variable bit } \\
\text { interleaved coding } \\
\text { for high bandwidth } \\
\text { efficiency }\end{array}$ & $\begin{array}{l}\text { Adaptive bit } \\
\text { interleaved coded } \\
\text { modulation is } \\
\text { suggested instead of } \\
\text { TCM }\end{array}$ & $\begin{array}{l}\text { Gain in terms of SNR and } \\
\text { Throughput }\end{array}$ \\
\hline 2002 & $\begin{array}{l}\text { Xiaodong Li, Aik } \\
\text { Chindapol, James A. } \\
\text { Ritcey[8] }\end{array}$ & $\begin{array}{l}\text { BICM with iterative } \\
\text { decoding and } 8 \text { PSK } \\
\text { signalling }\end{array}$ & $\begin{array}{l}\text { Suggests BICM with } \\
\text { iterative decoding } \\
\text { having large diversity } \\
\text { with small Euclidean } \\
\text { distance }\end{array}$ & Bandwidth efficiency \\
\hline 2006 & $\begin{array}{l}\text { Naghi H. Tran and Ha } \\
\text { H. Nguyen[9] }\end{array}$ & $\begin{array}{l}\text { 8-ary constellation } \\
\text { signal mapping for } \\
\text { bit interleaved code } \\
\text { modulation with } \\
\text { iterative decoding }\end{array}$ & $\begin{array}{l}\text { Suggested 8-ary } \\
\text { constellation signal } \\
\text { mapping for BICM- ID } \\
\text { depending upon } \\
\text { Euclidean distance and } \\
\text { mutual information }\end{array}$ & $\begin{array}{l}\text { Minimize bit error rate at high } \\
\text { signal to noise ratio }\end{array}$ \\
\hline 2011 & $\begin{array}{l}\text { Md. Jahangir Hossian, } \\
\text { Alex Alvarado, Laszek } \\
\text { Szczecinski[10] }\end{array}$ & $\begin{array}{l}\text { Interleaver and } \\
\text { constellation design } \\
\text { for bit interleaved } \\
\text { coded modulation }\end{array}$ & $\begin{array}{l}\text { Hierarchical } \\
\text { constellation are } \\
\text { suggested to protect a } \\
\text { data stream from } \\
\text { channel impairments }\end{array}$ & $\begin{array}{l}\text { Bit error rate for single data stream } \\
\text { is improved }\end{array}$ \\
\hline 2016 & $\begin{array}{l}\text { Hongzhong Yan and } \mathrm{Ha} \\
\text { H. Nguyen[11] }\end{array}$ & $\begin{array}{l}\text { BICM-ID in two } \\
\text { way transmitting } \\
\text { communication }\end{array}$ & $\begin{array}{l}\text { With BICM-ID IS two } \\
\text { way relaying } \\
\text { communication is } \\
\text { proposed for multiple } \\
\text { access phase }\end{array}$ & $\begin{array}{l}\text { Bit error rate diminished by using } \\
\text { iterative decoding and XOR based } \\
\text { network coding }\end{array}$ \\
\hline
\end{tabular}

\section{CONCLUSION}

This paper reviews the performance comparison of two coded modulation techniques - trellis coded modulation and Bit interleaved coded modulation.TCM offers more coding gain without compressing bandwidth by maximizing the free Euclidean distance among coded signal while BICM uses hamming distance to increase diversity order and with increased diversity order bit error rate diminishes. Unlike in TCM, BICM consider coding and modulation as two distinct operations which lead to provide more flexibility in design and implementation.

\section{REFERENCES}

[1] Giuseppe Carie, Giorgio Taricco and Ezio Biglieri, "Bit Interleaved coded modulation", IEEE Transactions on information Theory, Vol. 3, No.3, pp 927- 946, May 1998.

[2] LEE - FANG WEI, "trellis coded modulation with multidimensional constellation", IEEE Transactions on 
Information Theory, volume IT-33,No.4, pp 483- 501, July 1987.

[3] Dariush divsalar and Marvin K. Simon, "Trellis coded modulation for 4800-9600 bits per second transmission over a fading mobile satellite channel", IEEE Journal on selected Areas in Communication, Vol. Sec-5, No.2, pp 162-175, February 1987.

[4] Dariush divsalar and Marvin K. Simon, "Multiple trellis coded modulation", IEEE Transactions on communication, Vol.36, No. 4, pp 410-419, April 1988.

[5] Michael L. Moher and John H. Lodge, "TCMP - A Modulation and coding strategy for Racian Fading Channels", IEEE Journal on selected Areas in Communication, Vol.7, No.9, pp 1347- 1355, December 1989.

[6] G.Caire, G.Taricco, E.Biglieri, "bit interleaved coded modulation", communications, 1997, ICC '97 Montreal, Towards the Knowledge millennium. IEEE International conference, 12 june 1997.

[7] Vincent K.N. Lau, "Performance of variable bit interleaved coding for high bandwidth efficiency", The $51^{\text {st }}$ IEEE V T S
Vehicular technology conference proceedings, spring, Tokyo, japan, vol.3, pp 2054-2058, 15-18 May 2000.

[8] Xiaodong Li, Aik Chindapol, James A. Ritcey, "bit interleaved coded modulation with iterative decoding and 8 PSK signalling", IEEE Transactions on communication Vol. 50, No.8, august 2002.

[9] Naghi H. Tran and Ha H. Nguyen, "signal mapping of 8 - ary constellation for bit interleaved coded modulation with iterative decoding". IEEE Transactions on Broadcasting, Volume 52, No.1, pp 92-99, March 2006.

[10] Md. Jahangir Hossian, Alex Alvarado, Laszek Szczecinski, "Constellation and Interleaver design for bit interleaved coded modulation", Global Telecommunication Conference (GLOBECOM 2011), IEEE, 5-9 December 2011.

[11] Hongzhong Yan and Ha H. Nguyen,"Bit interleaved coded modulation with Iterative decoding in two way relaying communication", IEEE International Conference on communications (ICC) ,22-27 may 2016. 